
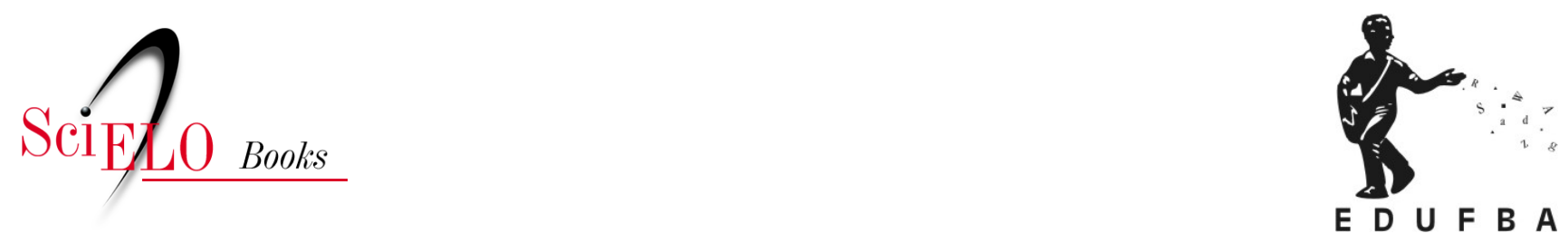

\title{
A criação da ECT e a corporatização do setor postal brasileiro (1969-1990)
}

\author{
Tadeu Gomes Teixeira
}

TEIXEIRA, T.G. A criação da ECT e a corporatização do setor postal brasileiro (1969-1990). In: Os Correios e as politicas governamentais: mudanças e permanências [online]. Salvador: EDUFBA, 2016, pp. 37-63. ISBN: 978-85-232-2025-9. https://doi.org/10.7476/9788523220259.0004.

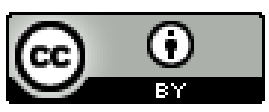

All the contents of this work, except where otherwise noted, is licensed under a Creative Commons Attribution 4.0 International license.

Todo o conteúdo deste trabalho, exceto quando houver ressalva, é publicado sob a licença Creative Commons Atribição $\underline{4.0}$. 


\section{A criação da ECT e a corporatização do setor postal brasileiro (1969-1990)}

A onda de transformações no contexto do setor postal internacional a partir da década de 1980 influenciou os rumos do setor postal brasileiro. No entanto, enquanto os agentes públicos no cenário internacional estudavam medidas para transformar os operadores públicos em corporações, o Brasil já dispunha, desde 1969, de uma empresa pública responsável pelo sistema postal nacional.

Com isso, analisam-se neste capítulo a corporatização dos Correios e suas implicações para a gestão do sistema postal brasileiro até a década de 1990. Discutem-se as características resultantes desse processo para a regulação do mercado, para a organização do trabalho e para as políticas de gestão da força de trabalho, bem como para as relações de trabalho. Com isso, pretende-se mostrar que a "onda de transformações postais" que assolava o cenário internacional encontraria no Brasil um sistema postal bastante diverso.

\section{O PIONEIRISMO BRASILEIRO NA CORPORATIZAÇÃO POSTAL: A CRIAÇÃO DA EMPRESA BRASILEIRA DE CORREIOS E TELÉGRAFOS}

O setor postal brasileiro está em operação desde o século XVII. Contudo, dois momentos marcaram os Correios: a década de 1930, com a criação do Departamento de Correios e Telégrafos, e a década de 1960, quando houve o processo de corporatização do sistema postal brasileiro.

Durante o período da República Velha, o sistema postal brasileiro ficou marcado, segundo Barros Neto (2004), pela ineficiência e ausência de 
planejamento, atrasos na entrega das correspondências e ausência de regulação. Em 1930, Getúlio Vargas ascendeu ao poder e iniciou uma série de reformas que, em interface com o contexto socioeconômico, impactaram os serviços postais. Uma nova dinâmica econômica acentuou-se durante o Governo Vargas (1930-1945), favorecendo os projetos de acumulação baseados na industrialização e o desenvolvimento de estruturas administrativas burocráticas. Nesse período, portanto, houve não só uma reformulação do Departamento de Correios, mas também um esforço para o soerguimento dos demais órgãos da administração pública.

Apesar da deterioração dos serviços postais no início da Era Vargas, a chamada Revolução de 1930 foi realizada com o auxílio de telegramas (BARROS NETO, 2004), o que evidencia a importância de tal veículo para a comunicação nacional e também para a própria atividade política à época. Diante disso, uma intervenção no setor pelo novo governo era previsível. Nesse sentido, Getúlio Vargas determinou, em 1931, a fusão da Direção Geral dos Correios com a Repartição Geral de Telégrafos, originando o Departamento de Correios e Telégrafos (DCT). Continuou a ser, portanto, um órgão diretamente vinculado ao Estado brasileiro.

Ainda na década de 1940 e 1950, o DCT investiu na criação do Correio Aéreo Nacional. Beneficiou-se, portanto, da obrigatoriedade do transporte, pelas companhias aéreas, das malas postais, e também da nova regulamentação dos serviços postais, que seriam monopolizados pela União (transporte e distribuição de objetos postais com caráter de mensagem).

Os anos da década de 1960 foram caracterizados por intensa crise econômica, política e social. Nessa conturbada década houve o golpe militar em 1964 e a implantação da ditadura militar, intensificando o projeto de modernização autoritária da economia brasileira.

A situação no então DCT começou a se mostrar problemática logo nos primeiros anos da década de 1960, quando a qualidade dos serviços postais deteriorou-se. As tarifas postais, mesmo diante do processo inflacionário do período, não foram reajustadas e os recursos para manutenção das operações postais que deveriam ser repassados pelo Tesouro Nacional escassearam, ficando o DCT impedido de investir na reformulação de suas atividades. Segundo Barros Neto (2004, p. 47), "era de conhecimento de 
toda a sociedade a falta de adequada política tarifária, a precariedade das instalações e o despreparo do pessoal", elementos que contribuíam para a ineficiência do setor.

Os serviços prestados eram os básicos - transporte de cartas e encomendas -, e mesmo assim com baixa qualidade. Os problemas ocorriam principalmente pela frágil infraestrutura dos serviços operacionais de distribuição postal e da rede telegráfica. Todavia, o setor administrativo do DCT também não acompanhava o desenvolvimento adequado e necessário às atividades operacionais.

Com isso, o Departamento de Correios tornou-se novamente símbolo da ineficiência nos serviços públicos. Além disso, nem a estrutura burocrática iniciada sob orientação do DASP, nas décadas de 1930 e 1940, era seguida, já que havia uma transferência de funcionários de outros órgãos da administração para os quadros do DCT sem as devidas habilidades, além de uma enorme centralização e clientelismo marcando as relações entre funcionários e poder público. Se não bastasse, até mesmo uma subcontratação funcional existia no Departamento, isto é, a contratação de pessoas por funcionários para substituí-los em seus postos de trabalho, e com anuência das chefias. (BARROS NETO, 2004)

Diante disso e da necessidade de ampliar a prestação de serviços postais, os militares - que governavam o país e administravam diretamente os Correios - deram início a um processo de reformulação e reorganização dos serviços postais e de comunicação no país já na segunda metade da década de 1960.

Nesse sentido, com a criação do Ministério das Comunicações, em 1967, os serviços postais iniciaram uma nova fase, passando o DCT à subordinação deste ministério. Além disso, os militares decidiram transformar, em 1969, o Departamento de Correios e Telégrafos na atual Empresa Brasileira de Correios e Telégrafos (ECT).

Com a criação da ECT, o general Rubem Rosado - até então presidente da empresa - foi substituído pelo coronel reformado do exército Haroldo Corrêa de Mattos. O objetivo do coronel Mattos era proporcionar à ECT uma gestão próxima da racionalidade técnica, adequando a empresa à lógica do setor privado. Para isso, o coronel contava com os instrumentos da 
reforma administrativa de 1967, incorporada ao aparato legal por meio do Decreto-Lei no. 200, de 25 de fevereiro de 1967, segundo o qual as atividades do Estado seriam realizadas por entidades da Administração Direta (vinculadas à presidência da República e ministérios) ou indireta (órgão com natureza jurídica própria), como autarquias, empresas públicas, sociedades de economia mista e fundações.

Assim, o Decreto-Lei no. 509, de 20 de março de 1969 - decreto de criação da ECT-, enfatiza o caráter empresarial da nova organização, alterando, portanto, o sentido de sua vinculação ao Estado e suas obrigações administrativas.

Com isso, os Correios passaram a transitar entre duas lógicas administrativas: uma empresarial e outra pública. Garantiu-se à empresa a manutenção de seu patrimônio como pertencendo integralmente à União. Além disso, garantiu-se autonomia à ECT para escolher - como na lógica empresarial - as estratégias de gestão que deviam guiá-la para, como em uma empresa privada, buscar a eficiência e o lucro em suas operações.

A criação da ECT não alterou significativamente a estrutura que já existia no DCT. Assim, a empresa continuou a funcionar com base nas Diretorias Regionais subordinadas à administração central, sediada em Brasília. Havia em 2011 vinte e oito Diretorias Regionais, ${ }^{5}$ responsáveis por coordenarem as atividades operacionais e administrativas em cada estado da Federação. A administração central, subordinada desde a criação ao Ministério das Comunicações, dispunha de uma presidência e vice-presidências responsáveis por áreas específicas.

Para assessorar as Diretorias Regionais, foram criadas gerências para dar suporte aos negócios da empresa, como, por exemplo, a Gerência de Qualidade, de Relações do Trabalho, de Recursos Humanos etc. As atividades operacionais da empresa - captação, triagem e transporte, e distribuição domiciliária - estão subordinadas, no âmbito nacional, à

5 A empresa explica, em seu site oficial na internet, que "o Estado de São Paulo é dividido em duas diretorias: São Paulo Metropolitana, com atuação na capital e Baixada Santista, e São Paulo Interior, responsável pelos demais municípios. A Diretoria Regional de Brasília abrange o Distrito Federal e alguns municípios do interior do Estado de Goiás. As demais Regionais atuam na área correspondente aos limites geográficos dos respectivos Estados". 
Vice-Presidência de Operações e às Gerências dos Centros de Tratamento de Cartas e Encomendas de cada diretoria regional.

A estrutura organizacional da ECT nesses moldes, apesar de algumas mudanças nas nomenclaturas, só foi alterada novamente durante o governo da presidente Dilma Rousseff.

Diante desses elementos, verifica-se que a transformação do DCT em ECT foi uma estratégia pioneira da ditadura militar no contexto internacional. A mudança concatena-se ao processo de corporatização, isto é, de desvinculação dos serviços postais dos departamentos de Estado e sua conversão em empresas públicas autônomas. No cenário internacional, como foi discutido no capítulo precedente, processo semelhante só seria realizado na maior parte dos países da OCDE a partir do final da década de 1980. Quais as repercussões dessas transformações para o mercado postal? É o que se discute na próxima seção.

\section{O MERCADO POSTAL COM A CORPORATIZAÇÃO: DO MONOPÓLIO COMO "CASO DE POLÍCIA" AO LOBBY INTERNACIONAL}

O Decreto-Lei no. 509, de 1969, definiu em seu artigo $2^{\circ}$ e inciso I a estrutura do mercado postal e o papel da ECT, responsável por "executar e controlar, em regime de monopólio, os serviços postais em todo o território nacional." ${ }^{\prime 2}$ Também se regulamentou no Código de Processo Penal que aqueles que violassem o monopólio estariam sujeitos a prisões e multas. Em consequência disso, durante a década de 1970 os diretores da estatal empreenderam várias ações para coibir a violação ao monopólio.

Nesse sentido, em 1973 a Folha de São Paulo informava, em reportagem intitulada Irregularidade na entrega de cartas, que "Fiscais da Diretoria Regional da ECT suspenderam todas as atividades da Entregadora Carlos Pereira de Castro - uma das maiores da capital - que, utilizando-se do nome fictício de 'Servbank', realizava o transporte paralelo de correspondências para três bancos". De acordo com a reportagem, "Essa é a primeira

6 O âmbito de atuação da ECT passou a ser também o mercado internacional a partir da Lei no. 12.490, de 16 de setembro de 2011. 
de uma lista de 20 entregadores já em poder do diretor regional da ECT, Coronel Adwaldo Cardoso Botto de Barros, que estão atuando na área da Capital, Santos, Campinas e São Bernardo como 'correio paralelo' a serviço de inúmeras firmas".

Interessante destacar que, além da criminalização da violação ao monopólio postal, as denúncias chegavam ao conhecimento da diretoria dos Correios por meio de denúncias anônimas. Isso resultava, como mostra a reportagem, em uma verdadeira investigação policial para combater a violação ao monopólio por parte dos integrantes das forças armadas que administravam a ECT.

Aparece também na reportagem um argumento que se tornou recorrente nas décadas seguintes: a possível relação de causalidade entre quebra do monopólio e falência da empresa. Nesse sentido, o coronel diretor da ECT afirmara que "a situação não está nada boa no setor, porque já estamos com os nomes de mais de 20 empresas que estão funcionando como 'correio paralelo' sem qualquer autorização, realizando um serviço exclusivo da EBCT”. Assim, não é de se estranhar que em 1974 a Polícia Federal tenha indiciado um representante da empresa Mensageiro Bandeirante Ltda. por violação ao monopólio. (VIOLAÇÃO..., 1974)

$\mathrm{Na}$ década de 1970, houve inúmeros incidentes que exemplificam a disputa entre empresas privadas e a ECT, inclusive com possibilidade de prisão para empresários. (HABEAS-CORPUS..., 1975) Essa década, portanto, pode ser caracterizada como um período em que a violação ao monopólio era efetivamente um caso de polícia.

Os esforços para garantir o monopólio foram reforçados ao final da década, quando foi promulgada a Lei no. 6.538, de 22 de junho de 1978, responsável pela regulamentação dos serviços postais nas três décadas seguintes e por estabelecer a competência da ECT e as diretrizes para o setor postal brasileiro. Por essa Lei Postal - como ficou conhecida garantiu-se o monopólio postal aos Correios para os serviços de cartas, cartões postais, telegramas e malotes, possibilitando a livre concorrência somente na entrega dos objetos postais não reservados. Além disso, foram estabelecidas multas e até mesmo detenção para os que violassem a restrição de mercado. 
A partir desse arcabouço legal, o monopólio foi reiterado e garantido à ECT. No entanto, na década de 1980 as transformações socioeconômicas reservaram uma nova disputa em torno da questão. Agora, seria preciso enfrentar as multinacionais que buscavam atuar no mercado postal brasileiro. Se na década anterior o monopólio se restringiu a um caso de polícia, os anos de 1980 impuseram aos Correios uma atuação também na esfera política para defesa do monopólio.

No início daquela década, multinacionais como DHL, World Courrier e Choise Air International começaram a atuar no mercado postal brasileiro, principalmente na remessa internacional de objetos postais. Para isso, no entanto, precisavam de autorização legal. Nesse sentido, em 1982 essas empresas obtiveram a aprovação de um projeto de lei na Câmara dos Deputados. Encaminhado ao Senado, ele só teve visibilidade quando já estava prestes a ser votado. A proposta era aprovar a abertura do mercado de malotes internacionais à concorrência, o que atendia aos anseios de multinacionais. De acordo com o Ministério das Comunicações, "a posição oficial é de total repúdio do projeto e pela manutenção do monopólio postal". (GOVERNO..., 1983) À época, empresas brasileiras de correios não pretendiam atuar na esfera internacional, o que evidencia que apenas os empresários estrangeiros pressionavam pela abertura do mercado nacional. O interesse pelo setor devia-se, evidentemente, à sua lucratividade, que também servia para a ECT subsidiar as tarifas domésticas.

Segundo o coronel Adwaldo Cardoso Botto de Barros, presidente da ECT até 1985, a disputa envolvia mais que grupos empresariais multinacionais, já que seus interesses eram reiterados pelo governo dos Estados Unidos em pressões ao governo brasileiro. (PRESIDENTE..., 1984) Todavia, compromissos foram firmados para a manutenção do monopólio até mesmo pelo presidente eleito Tancredo Neves. Apesar disso, as multinacionais continuaram a pressionar o governo brasileiro pela abertura do mercado internacional de malotes e algumas conseguiram autorização para atuar. Mesmo assim, o monopólio da ECT mesmo para transporte internacional de malotes foi garantido naquele momento.

Um episódio marcante que acirrou o embate entre ECT e as multinacionais ocorreu em 1989. Dando continuidade à lógica policial de combate à 
violação ao monopólio, a estatal acionou a Polícia Federal em uma operação de fiscalização e combate à quebra do monopólio pelas empresas de "air courier". Na operação, cinquenta e três empresas foram autuadas por violar o monopólio e mais de quinze mil objetos postais foram apreendidos. (PF..., 1989)

Esse caso teve uma repercussão internacional. Na ocasião, a International Express Carriers Conference (IECC) - associação mundial que reunia, por exemplo, empresas como UPS, DHL, FEDEX, TNT etc. - convocou uma reunião extraordinária com a então Associação Brasileira de Empresas Courier (ABRAEC) para debater o caso. O intuito da IECC na ocasião era acusar o Brasil de ser contrário ao livre mercado e exigir retaliações dos governos dos Estados Unidos e da então Comunidade Econômica Europeia. A ABRAEC, no entanto, informou que conseguira convencê-los acerca da possibilidade de resolver o impasse no Brasil, sem necessidade de recorrer aos organismos internacionais. Para isso, agendaram-se reuniões e debates acerca do entendimento da Constituição Federal aprovada naquele ano sobre o assunto. Para a ABRAEC, outra operação similar por parte da ECT seria temerária, porque poderia desencadear disputas comerciais de âmbito internacional. Para a ECT, no entanto, ela só estava cumprindo o que garantia a legislação e, portanto, defendendo o monopólio postal. (CONFLITO..., 1989)

A década de 1980, assim, foi marcada pela disputa entre a ECT e multinacionais interessadas na quebra do monopólio de remessas internacionais de malotes, com eventuais acirramentos da disputa e envolvimento da Polícia Federal para coibir as violações. Essa década, entretanto, também assistiu à consolidação da presença de empresas postais transnacionais no Brasil que passaram a lutar, com estratégias políticas e econômicas, pelos seus interesses corporativos.

Não obstante os esforços da ECT para manutenção do monopólio postal, com a eleição do presidente Fernando Collor de Melo, em 1990, e com a adoção do "Plano Collor", levando à consequente abertura comercial brasileira, as empresas de courier obtiveram uma vitória parcial, podendo desde então atuar no segmento postal internacional. Como representante do projeto neoliberal, novas estratégias dos grupos corporativos dominantes passaram, a partir de então, a orientar as ações desse governo. 
Com a abertura comercial, a expectativa das empresas multinacionais passou a ser a expansão de sua atuação no mercado postal brasileiro. Para os representantes dessas empresas, o tráfego postal poderia ser incrementado com a abertura às importações pelo governo Collor, o que favoreceria diretamente as empresas de courier. Essa era a previsão, por exemplo, da TNT Skypak International Express, cujo diretor executivo afirmou: "[...] as perspectivas em médio prazo são boas, porque com as novas medidas poderemos partir com mais força em busca da liderança do mercado". (STULMAN, 1990, p. 08) Apesar disso, a ECT, em 1992, continuava a solicitar à Polícia Federal a apreensão de objetos postais entregues em território brasileiro por empresas privadas que não trabalhassem com courier. Ainda naquele ano, diante de ação da ECT contra uma empresa paulista, ela questionou judicialmente a validade do monopólio postal da União em todos os segmentos de mercado. (EMPRESA..., 1992) Isso indica que já no início da década empresas atuantes no mercado postal brasileiro passaram a agir com mais desenvoltura no combate ao monopólio postal.

A partir da corporatização, a ECT também buscou ampliar suas estratégias mercadológicas, como será apresentado a seguir.

\section{ESTRATÉGIAS MERCADOLÓGICAS}

O coronel Haroldo Corrêa de Mattos, ao liderar o processo de transformação dos Correios, objetivava proporcionar à ECT mecanismos de gestão consoantes à lógica de mercado. Para isso, adotou o planejamento nas atividades de gestão da empresa e investiu em bancos de dados e em índices de produtividade do trabalho. Com isso, tentou diminuir a influência e apadrinhamento de antigos grupos políticos na ECT e criar uma linha de comando nacional. (VERGARA; CAVALVANTI, 1995a)

A ECT buscou ampliar, a partir de 1970, as opções de serviços prestados aos seus clientes, principalmente em relação aos serviços expressos, e oferecer serviços mais ágeis. Para viabilizar a estratégia, a ECT substituiu o transporte ferroviário pelo rodoviário, criando entroncamentos e linhas especiais para o transporte regional e nacional de carga postal. Ampliou o número de agências e o serviço de distribuição domiciliária. 
Para agilizar o processo de encaminhado postal e atribuir-lhe uma lógica de endereçamento, criou o código de endereçamento postal - CEP - ainda em 1971.

As estratégias de marketing somam-se a essas mudanças, enfatizando a satisfação dos clientes e investindo nos programas sociais oficiais do governo federal ao prestar apoio por meio de sua logística e inserção pulverizada no país. A década de 1970 foi, portanto, de incremento nas atividades da ECT, sobretudo pela reformulação de seus serviços e ampliação da cobertura e abrangência nacional, além da padronização de serviços. Essas mudanças se estenderam pela década de 1980. Em 1982 foi criado o Serviço de Entrega Expressa (SEDEX) que, a partir de então, marcaria a identidade da empresa em decorrência da promessa de entrega em $24 \mathrm{~h}$ depois da data de postagem nas principais capitais (padrão de entrega chamado D+1: dia da postagem mais um para entrega). (VERGARA; CAVALCANTI, 1995b)

Desde a década de 1970, a década do "milagre econômico" brasileiro, a evolução do tráfego postal vinha crescendo a taxas superiores a $18 \%$ ao ano. Nos anos 1980, no entanto, as taxas de crescimento postal se estabilizaram em 3,2\% em decorrência da recessão econômica ocorrida no período, como mostram Vergara e Cavalcanti (1995c). Ao mesmo tempo, o congelamento dos preços pelo Plano Cruzado comprimiu as tarifas postais, diminuindo as receitas operacionais. Isso, por sua vez, reduziu os investimentos na empresa de $12 \%$ da receita, nos anos 1970, para menos de $3 \%$ na década seguinte.

Diante desse cenário, em seu plano estratégico para a década de 1990 a ECT alegou ser necessário diversificar sua atuação em segmentos alternativos à entrega de cartas, telegramas e encomendas, isto é, que a empresa investisse em outras fontes de receitas para além dos serviços sob reserva de mercado. Com isso, os Correios passaram a diversificar os seus serviços a partir das agências de atendimento e das possibilidades logísticas.

Assim, a ECT passou a oferecer diversos outros serviços em suas agências de atendimento (solicitação e entrega de passaportes, entrega de carteira nacional de habilitação, venda de fichas e cartões telefônicos, pagamento de benefícios sociais a partir de convênio com órgãos 
governamentais etc.) e também a transportar produtos e mercadorias que até então não integravam suas atividades.

Com essas estratégias mercadológicas, a empresa conseguiu aumentar seu faturamento de US\$ 890 milhões, em 1989, para quase US\$ 1,5 bilhão em 1992. A despeito desse crescimento no faturamento, a ECT passou a alegar falta de recursos para continuar a investir na modernização e ampliação dos serviços. (VERGARA; CAVALCANTI, 1995c) Assim, ao adentrar a década de 1990, a ECT buscava estratégias e alternativas para incrementar a sua margem de faturamento para ampliar os investimentos. Ao mesmo tempo em que houve a busca pela diversificação das estratégias mercadológicas, as atividades de trabalho foram reorganizadas como forma de aumentar a produtividade e qualidade dos serviços.

\section{A ORGANIZAÇÃO DO TRABALHO NO CONTEXTO DA DITADURA MILITAR}

Nas décadas de 1940 e 1950, instituiu-se a triagem manual de correspondências nos Correios, organizando o trabalho operacional e mostrando o caminho para a estruturação das atividades nos centros de tratamento e distribuição nas décadas seguintes. Os métodos de trabalho no final da década de 1960, no entanto, eram tidos como ineficientes e obsoletos e o sucateamento das instalações somava-se ao quadro. (BARROS NETO, 2004)

O diretor da ECT na década de 1970, coronel Haroldo Corrêa de Mattos, tinha como missão soerguer a ECT a partir de transformações na estrutura e nos serviços da empresa. Para isso, contava não só com os instrumentos e aparatos técnico-administrativos como também com a lógica de poder militar que o acompanhou em suas atividades gerenciais.

Como mostrado até o momento, a transformação dos Correios em empresa pública foi importante não só por alterar a estrutura e forma de vinculação ao Estado, mas também por propiciar a adoção de estratégias norteadas pela lógica de mercado. Nessa direção, houve em um primeiro momento, portanto, a reformulação administrativa da empresa e, posteriormente, da área operacional. Nesse sentido, o coronel Haroldo Corrêa 
de Mattos desencadeou o processo de estruturação e organização do trabalho na ECT na década de 1970.

Para realizar a estruturação e organização do processo operacional, a ECT contratou especialistas da área postal oriundos de empresas francesas, consideradas então as melhores do mundo. Foram realizadas quatro missões de trabalho pelos consultores postais franceses entre 1971 e 1977, sobretudo de funcionários das empresas Somepost e Sofrepost. Dois contratos foram assinados: o primeiro para diagnóstico global da situação do processo de trabalho e para avaliação técnica do serviço postal e o segundo para proposição de medidas de modernização.

Os consultores elaboraram relatórios acerca das condições encontradas na ECT à época e recomendaram mudanças nos procedimentos de trabalho. Além disso, prepararam a estruturação dos processos operacionais, momento em que transferiram o know-how que possuíam para técnicos e funcionários da ECT. (BARROS NETO, 2004; BOVO, 1997)

As missões e projetos de consultoria resultaram no Projeto Eco, assim denominado em decorrência de seus objetivos que precisavam ser "ecoados" por todas as áreas da empresa para iniciar uma "nova etapa nos serviços postais". Com esse projeto, toda a estrutura operacional e administrativa da ECT foi repensada, o que resultou em 28 relatórios, indicando como os serviços postais deveriam ser concebidos e realizados.

Um dos aspectos ressaltados nesses relatórios, segundo Bovo (1997, p. 39), é a enorme dependência que os serviços postais têm da mão de obra operacional. Os consultores das missões francesas, ao se depararem com o contingente de mão de obra na ECT, fizeram as seguintes considerações:

[...] o correio é, antes de tudo, uma empresa de mão-de-obra que, com exceção do setor de transportes, necessita muito mais de homens do que de máquinas; o funcionário do guichê será insubstituível ainda por muito tempo e no momento não vemos que substituto dar ao carteiro. Somente os grandes centros de triagem começam a ser dotados de poderosos meios mecânicos e automáticos, tais como transportadores aéreos ou esteiras, máquinas de triar cartas ou encomendas etc.

E complementam: "É importante assinalar que, apesar da utilização mais freqüente de máquinas de triar, no futuro a distribuição postal 
continuará dependendo do elemento humano". E por fim concluem: "Com efeito, para as tarefas de entrega a domicílio, o homem não pode ser substituído pela máquina." (RELATÓRIOS DAS MISSÕES FRANCESAS apud BOVO, 1997, p. 39)

Diante dessas análises acerca da força de trabalho nos serviços postais, os consultores franceses e os técnicos da ECT focaram seus esforços na apresentação de estratégias de gestão que não necessitassem, imediatamente, de mediação por processos mecanizados ou automatizados. Todavia, a mecanização e a automação só tomariam vulto na década de 1990. No contexto da década de 1970, as intervenções gerenciais visavam, portanto, a adoção de métodos de gestão focados no controle, disciplina e racionalização da força de trabalho.

Nesse sentido, os relatórios produzidos expressam a concepção ideológica e gerencial que seria adotada na ECT. De acordo com as análises realizadas,

Uma organização racional do trabalho constitui o meio mais seguro para se fazer economias, pois ela acarreta a supressão de trabalhos inúteis. (Grifo nosso)

A organização científica do trabalho tem outra finalidade, obter o melhor rendimento com o mínimo de esforço e ao menor custo. (Grifo nosso)

O estudo do funcionamento e da organização da maior parte do centro de triagem do país permitiu constatações passíveis de serem utilizadas na construção de uma organização racional de um centro de triagem de média importância [...]. (RELATÓRIOS DAS MISSÕES FRANCESAS apud BOVO, 1997, p. 47, grifo nosso)

Ao adotar essa concepção de racionalização do processo de trabalho, vinculada à administração científica e consoante aos processos de rotinização adotados então pelos empresários brasileiros (FLEURY, 1983), os consultores franceses e os técnicos da ECT alinhavam-se ao lado do processo de racionalização da produção que ocorria no Brasil desde a década de 1960 e que se intensificou na década de 1970, de acordo com Fleury e Vargas (1983). Nessa década, as empresas brasileiras racionalizavam o seu processo de produção ao introduzirem técnicas consoantes ao modelo taylorista 
de organização do processo de trabalho. O taylorismo é, como argumentam Braverman (1987) e Perrot (1989), o ápice de um processo social que objetivava impor o controle, a ordem e a disciplina sobre os trabalhadores.

A partir da concepção taylorista que orientava os consultores franceses e os técnicos da ECT, as seguintes análises foram feitas sobre o processo de trabalho:

Por falta, às vezes, de documentos escritos e freqüentemente pela ausência de fiscalização e de autoridade dos chefes de turma os horários de fechamento são deixados à iniciativa dos servidores. [...] A simples presença de monitores de triagem no centro, após um período de formação e recebendo todo o apoio das autoridades hierárquicas, poderia eliminar maus hábitos contraídos durante anos pelo pessoal, entregue até então à sua própria vontade. [...] na maioria das vezes o carteiro era o único funcionário que sabia exatamente como era feita, na verdade, a distribuição externa. [...] O encaminhamento a ser dado a uma correspondência e a lista das malas a ser formada não devem ser deixadas à iniciativa dos funcionários do centro de triagem. (RELATÓRIOS DAS MISSÕES FRANCESAS apud BOVO, 1997, p. 44-45, grifo nosso)

Em relação ao serviço do carteiro, cuja participação no contingente de funcionários da empresa era dos maiores, as atividades foram reelaboradas a partir das análises referentes à tarefa, como se observa nos seguintes excertos:

[...] (a) organização e definição de itinerários de distribuição externa, que não deveriam ficar mais a critério dos carteiros, visando criar na clientela o hábito de ver o carteiro passar numa hora certa, dando à Empresa a possibilidade de controlar o funcionamento da distribuição externa. [...] Em nenhuma hipótese, esta lista é deixada a critério do carteiro. [...] itinerário: não tendo sido organizado, ele era determinado diariamente pelo carteiro. (RELATÓRIOS DAS MISSÕES FRANCESAS apud BOVO, 1997, p. 45, grifo nosso)

Este último excerto indica o que não deveria acontecer em nenhuma hipótese: deixar ao carteiro o controle das atividades de trabalho. Sendo assim, é possível visualizar como o processo de estruturação e organização do trabalho na ECT foi conduzido na década de 1970. Tal análise dos consultores e formuladores do processo de gestão decorre do princípio 
taylorista que combatia a iniciativa do trabalhador e indicava a necessidade de se estabelecer uma separação entre o trabalho dos operários responsáveis pela execução das atividades produtivas e o trabalho dos responsáveis por conceber a organização do processo de trabalho. Essa concepção taylorista não ficou só no plano formal, mas transferiu todo o controle do processo produtivo às mãos da gerência, que passou a estipular, a partir de então, o controle e a fixação de cada fase da organização do trabalho, principalmente a maneira de executar as atividades de trabalho. (BRAVERMAN, 1987; FARIA, 2004)

Esse controle do trabalho, de acordo com a lógica taylorista, ficaria a cargo de um corpo gerencial específico, que realizaria o planejamento de todas as demais atividades de produção, baseava-se nos estudos de tempo de cada atividade. Para o taylorismo, além da expropriação do saber operário, era necessário controlar o ritmo e a intensidade do trabalho por meio de uma "análise científica". Dessa forma, um tempo padrão poderia ser estabelecido e considerado o "tempo ótimo" para cada atividade de trabalho. (BRAVERMAN, 1987; FARIA, 2004)

A partir disso, a ECT estabeleceu uma nítida separação entre o trabalho de execução e o setor responsável pela concepção das atividades de trabalho. Uma separação, portanto, entre execução e concepção. Assim, tornou-se necessária uma transferência do conhecimento dos trabalhadores sobre o processo de trabalho para os gestores da empresa, como prescrito no caso dos carteiros. Com essa lógica, os carteiros passaram a ter suas tarefas regulamentadas e controladas pela gerência responsável por conceber e determinar a rotina de trabalho.

Nesse período de estruturação da ECT, departamentos e gerências foram criados, em um processo que ampliava e diversificava a área de concepção do processo de trabalho. Consoante a isso, criou-se a Assessoria de Planejamento e Controle (APC), que ficou subordinada diretamente à Assessoria de Planos e Desenvolvimento (APD), situada em Brasília, na Administração Central. Além disso, em cada diretoria regional foi criado um setor de planejamento. (BOVO, 1997)

A APD não era somente mais uma gerência ou departamento, mas um órgão responsável por realizar diversos estudos, reorganizar e racionalizar 
o processo de trabalho. Dentre os estudos realizados pela APC, destaca-se o estudo de tempos e movimentos, de fundamental importância na modificação da cadência do trabalho nos Correios. Assim, verifica-se, a partir disso, a preocupação presente nos relatórios acerca da produtividade, do ritmo e do controle do trabalho:

A organização do trabalho tem outra finalidade, obter o melhor rendimento com o mínimo de esforço e ao menor custo. Por isso, todos os fatores elementares do trabalho devem ser dissecados e estudados, o que exige comparações estabelecidas através de medidas. Essas medidas são exprimidas pelos 'índices' ou 'coeficientes' de rendimentos.

A velocidade média de caminhada deve ser apreciada em cada cidade e em cada setor por uma série de acompanhamento de carteiros com capacidade física normal. (RELATÓRIOS DAS MISSÕES FRANCESAS apud BOVO, 1997, p. 47)

Diante disso, a ECT implantou o estudo e controle do tempo da seguinte maneira:

- decomposição dos trabalhos em elementos simples, isto é, a análise detalhada de todos os movimentos do trabalho. Isto se dá de forma esquemática e é denominada de fluxograma;

- registro do tempo para realização de cada movimento, por meio de um cronômetro e um contador de objetos; e

- determinação de um índice (ou coeficiente) para cada movimento. Esse índice expressa quanto tempo um funcionário leva para efetuar as operações (existe um índice para cada operação). De acordo com o estudo padroniza-se o tempo médio observado ou impõe-se novo tempo para realizar cada movimento.

Esses índices serão empregados para determinar o número de trabalhadores necessários em cada unidade de trabalho. É a chamada dotação de pessoal. O número de funcionários lotados jamais pode ultrapassar a dotação de cada unidade de trabalho. A dotação é calculada por meio da relação: quantidade de objetos manipulados versus índices dos movimentos a eles relacionados. Chega-se, assim, a um total de horas para a unidade de trabalho em questão e divide-se pela jornada de trabalho. Tem-se o número de trabalhadores necessários. (RELATÓRIOS DAS MISSÕES FRANCESAS apud BOVO, 1997, p. 49) 
Com isso, o que fica evidente na análise referente à busca pela separação entre execução e concepção do trabalho, além do controle do tempo e da intensidade do trabalho, é a origem e inspiração dos procedimentos nos princípios da administração científica. Esse estudo dos tempos e movimentos no taylorismo - e na ECT - visava alcançar o "rendimento ótimo", como dizia Taylor (1989), de cada trabalhador. Segundo Braverman (1987), "rendimento ótimo" no taylorismo se baseia unicamente nos critérios fisiológicos, referindo-se somente ao que o corpo físico pode suportar. Esses princípios proporcionaram uma nova dimensão ao controle fabril, de acordo com Braverman (1987, p. 86), já que o taylorismo “[...] elevou o conceito de controle a um plano inteiramente novo quando asseverou como uma necessidade absoluta para a gerência adequada a imposição ao trabalhador da maneira rigorosa pela qual o trabalho deve ser executado".

Corrobora-se essa análise quando se observa que a ECT criou uma nova função para integrar o quadro de funcionários nas unidades operacionais, o supervisor operacional, que ficou encarregado de fiscalizar o trabalho no interior desses espaços, como o serviço dos carteiros e operadores de triagem e transbordo dentro dos Centros de Distribuição Domiciliária, e mesmo o trabalho externo de distribuição de objetos postais. Esse supervisor, portanto, que visa controlar e fiscalizar as atividades de trabalho de funcionários lotados no "chão de fábrica" assemelha-se ao capataz preconizado pelo taylorismo para controlar o processo produtivo.

A ECT, como forma de reiterar o controle sobre os procedimentos de trabalho e averiguar se as unidades operacionais estavam efetivamente cumprindo com o que havia sido prescrito pelos departamentos de concepção, resgatou o trabalho da Inspetoria Regional - órgão que já existia em 1930 no Departamento de Correios e Telégrafos (DCT) - e reformulou suas funções, adequando-as às novas funções de supervisão das unidades operacionais.

À Inspetoria Regional coube o papel de censor e "conselheiro", já que deveria verificar os procedimentos de execução do trabalho e, ao mesmo tempo, propor mudanças, informar, "aconselhar" os gestores de unidades operacionais para que cumprissem as normas estabelecidas da forma mais conveniente e conforme o prescrito, além de mostrar como realizar tais procedimentos. Passou-se à responsabilidade da Inspetoria também a fiscalização 
do trabalho dos chefes de unidades operacionais a fim de verificar se eles desempenhavam suas funções de forma satisfatória, ou seja, se estavam cumprindo as decisões elaboradas pelas equipes dos departamentos de concepção da empresa, além de verificar assuntos relacionados aos problemas financeiros, materiais, sindicâncias e problemas com correspondências (como, por exemplo, investigar atrasos e violações de correspondências).

\section{POLÍTICAS DE GESTÃO DE PESSOAS NA FASE DE CORPORATIZAÇÃO}

Quando a ECT foi criada em 1969, os princípios da reforma administrativa expressos no Decreto-Lei no. 200, de 25 de fevereiro de 1967, já estavam em vigor. Com isso, os Correios tornaram-se parte da administração pública indireta e, assim, passaram a contratar os funcionários no regime da Consolidação das Leis do Trabalho (CLT). Dessa forma, os novos funcionários contratados pela ECT passaram a ser regidos pela legislação trabalhista e previdenciária, cabendo à Justiça do Trabalho a resolução de seus conflitos trabalhistas.

Tal fato teve como implicação uma transformação que só seria repetida no universo postal mundo afora na década de 1990: o reposicionamento dos funcionários dos Correios, que deixaram de estar vinculados ao regime do funcionalismo público e foram submetidos à CLT, ou seja, à lógica privada das relações empregatícias. Com isso, os trabalhadores dos Correios tornaram-se empregados públicos. À época, isso eliminou a obrigação da estatal de realizar concursos públicos ou seleções externas para contratação de seus funcionários. Esta situação perdurou até a Constituição de 1988, quando novamente concursos públicos ou seleções externas tornaram-se necessários para a contratação da força de trabalho para instituições da administração pública indireta.

Dessa forma, os novos funcionários contratados pela ECT passaram a ser regidos pela legislação trabalhista e previdenciária, cabendo à Justiça do Trabalho a resolução de seus conflitos trabalhistas. Por outro lado, as

exigências referentes aos servidores públicos continuaram a ser demandadas dos funcionários como, por exemplo, a proibição em acumular cargos públicos, aspecto típico da administração pública; além disso, os 
funcionários dos Correios foram proibidos de constituir sindicatos, apesar de serem regidos pela Consolidação das Leis do Trabalho. Dessa maneira, a ECT se converteu em uma entidade pública de direito privado com oscilações quando se trata de suas obrigações e/ou direitos.

A partir de 1969, portanto, a ECT passou a contratar os funcionários pelo regime CLT e a apresentar dois grupos de funcionários em seus quadros: os funcionários do antigo DCT regidos pelo Estatuto do Funcionalismo Público Federal (Lei no. 1.711, de 28 de outubro de 1952) e os contratados vinculados à CLT.

A existência de dois regimes de trabalho e os problemas decorrentes levou a empresa a formular e implantar em 1974 o primeiro Plano de Cargos e Salários, objetivando principalmente transferir os trabalhadores do antigo DCT para o regime celetista. Caso não aceitassem a proposta da empresa, seriam transferidos para outros órgãos da administração pública ou mesmo aposentados com vencimentos proporcionais ao tempo de trabalho. O primeiro plano de cargos e salários objetiva, portanto, unificar o regime de trabalho para, com isso, melhor gerenciar a força de trabalho. Cabe destacar que, com isso, a estabilidade no emprego se tornou inexistente para os antigos funcionários regidos pelo Estatuto do Funcionalismo Público Federal, facultando a livre demissão e contratação ao aderirem ao regime celetista. (BOVO, 1997) Com isso, a força de trabalho na ECT evoluiu da seguinte maneira entre 1969 e 1976:

TABELA 1 - EVOLUÇÃO DA FORÇA DE TRABALHO 1969 - 1976

\begin{tabular}{|l|l|l|l|}
\hline Ano & Estatutário & CLT & Total \\
\hline Dezembro 1969 & 57.457 & 6.083 & 63.540 \\
\hline Dezembro 1970 & 55.927 & 7.385 & 63.312 \\
\hline Dezembro 1971 & 54.565 & 9.771 & 64.336 \\
\hline Dezembro 1972 & 51.189 & 12.855 & 64.044 \\
\hline Dezembro 1973 & 57.528 & 17.201 & 74.729 \\
\hline Dezembro 1974 & 59.065 & 24.832 & 83.897 \\
\hline Dezembro 1975 & 2.727 & 50.468 & 53.195 \\
\hline Dezembro 1976 & 0 (zero) & 54.133 & 54.133 \\
\hline
\end{tabular}

Fonte: Departamento de Planejamento e Atendimento de Gestão de Pessoas - dados internos. 
Bovo (1997) explica que a ECT tentou desde a sua criação mudar o regime de trabalho dos funcionários para o celetista - ou emprestá-los a outros órgãos do governo. Por isso, segundo esse autor, em 1972 só $65,97 \%$ dos funcionários da ECT estavam diretamente vinculados às atividades da empresa.

A situação na ECT mudou com a aprovação da Lei nº 6.184, de 11 de dezembro de 1974, que garantiu aos estatutários que aderissem ao regime celetista a contagem do tempo trabalhado como funcionário público para a aposentadoria. (BOVO, 1997)

A eliminação do concurso público na ECT possibilitou, no contexto da ditadura militar e dos planos de organização dos processos de trabalho, a implementação de políticas de recrutamento e seleção baseadas nos princípios da administração científica visando à seleção do "candidato adequado" às estratégias de racionalização. (BOVO, 1997)

Em 1987 a ECT reformulou e implantou um novo Plano de Cargos e Salários e de Benefícios e Vantagens, tendo como pano de fundo o processo de estruturação das atividades operacionais. O principal destaque da reformulação está na unificação do cargo de carteiro. Até então, os carteiros eram organizados em quatro tipos: o carteiro lotado em centros de distribuição; o carteiro SERCA - responsável pela distribuição e coleta de encomendas expressas e malotes; o carteiro SEED - responsável pela distribuição de documentos oficiais; e o mensageiro, que atuava na área telegráfica. Com a unificação destes cargos, passou a existir apenas o cargo de carteiro, sendo os funcionários lotados em unidades operacionais segundo as atividades de distribuição, coleta e entrega de objetos postais.

Como parte das ações de treinamento e formação da força de trabalho, foram ministrados cursos de curta e média duração com os propósitos de melhorar a qualidade, aperfeiçoar e especializar os trabalhadores em suas operações na década de 1970. Eram treinamentos para o desempenho das funções. Segundo o coronel Mattos, de acordo com Vergara e Cavalcanti (1995a, p. 97), nas “[...] tarefas rotineiras não cabia a improvisação ou a criatividade do empregado, sob pena de perderem-se a agilidade, a uniformidade e a qualidade dos serviços prestados". Com isso, constata-se que o 
treinamento ministrado aos funcionários das atividades operacionais integrava uma concepção de trabalho alinhada ao mecanicismo taylorista.

Em 1971, para a formação de gestores, foi criado o Curso de Administração Postal em convênio com a PUC/RJ, que formou cinco turmas até 1978, totalizando 184 administradores postais. Como desdobramento, em 1978 a ECT criou a Escola Superior de Administração Postal (ESAP) com o objetivo de formar uma "elite de funcionários altamente capacitados para os postos de maior responsabilidade da Empresa", como "funções de Chefia, de Gerência, de Assessoria e atividades de Planejamento nos diversos órgãos da Administração Central e das Diretorias Regionais". (BARROS NETO, 2004, p. 77) A ESAP formou até 1999, quando as atividades foram interrompidas, ${ }^{7}$ mais de 1350 alunos.

Os alunos da ESAP, selecionados por meio de concurso, passavam também por um criterioso exame médico para admissão, semelhante ao que ocorre em instituições militares. Além disso, o curso funcionava em horário integral durante três anos, servindo como instrumento de disciplina e socialização de pares. Tratava-se de uma escola com o intuito de formar as lideranças da empresa conforme os que já administravam, isto é, conforme a lógica militar.

Nessas escolas, o que mais importava não eram as disciplinas cursadas, mas a socialização pela qual passavam os alunos/gestores, atualizando a diferenciação entre os níveis hierárquicos da empresa, refazendo a distância entre os líderes da organização e os demais trabalhadores que não pertenciam a essa "elite". A socialização dos novos funcionários com base nesses padrões era apenas, assim, questão de enquadramento pela convivência. Todos os novatos precisavam aceitar os valores compartilhados e se tornarem reprodutores das práticas de gestão vigentes, permitindo a reprodução dos comportamentos e práticas autoritárias na ECT e influenciando os rumos das relações de trabalho, como será mostrado a seguir.

7 Os cursos da ESAP não eram reconhecidos pelo Ministério da Educação como graduação. Em 2005, um convênio com a Universidade de Brasília possibilitou a criação da habilitação em Administração Postal no curso de Administração, marcando a retomada, em novos moldes, da proposta. 


\section{RELAÇÕES DE TRABALHO E O SURGIMENTO DAS ASSOCIAÇÕES SINDICAIS NA DÉCADA DE 1980}

O processo de organização e estruturação das atividades de trabalho na área operacional da ECT foi realizado em um contexto em que até mesmo os diretores dos Correios eram integrantes das Forças Armadas. Isso permitiu que as características dos métodos de organização do trabalho de inspiração taylorista encontrassem terreno propício em decorrência do autoritarismo militar.

Autoritarismo tipificado no número crescente de punições aplicadas no período pelas Inspetorias Regionais e pelos gestores das unidades operacionais, que visavam justamente enquadrar os trabalhadores da empresa na nova concepção de trabalho. (BOVO, 1997)

Os casos a seguir, relatados por funcionários da empresa, exemplificam as práticas autoritárias nas relações de trabalho nos Correios no contexto da ditadura militar:

Assim que os militares assumiram os correios a coisa ficou preta. Todo mundo tinha que trabalhar mesmo, não se tolerava mais atrasos, era muita pressão. Eu era um funcionário que tomava conta dos colegas lá na Vila Mariana, um cargo informal. De repente, um dia, o coronel me chama e mais todos aqueles que por algum motivo foram indicados como de confiança. Ele nos reuniu e disse que agora éramos monitores, que íamos tomar conta mesmo dos colegas de verdade, que tudo de errado tinha que ser informado. Eu pedi licença e falei que não queria, que preferia continuar a entregar cartas. O coronel disse, na frente de todo mundo, gritando, que quem manda agora sou eu, você só obedece e vai fazer o que eu estou mandando, seu FDP! Fiquei com vergonha e medo de ser preso ou alguma coisa parecida, mas aí tudo começou a melhorar, recebi aumento já no mês seguinte, depois fui fazer curso de supervisor, tudo ficou muito melhor do que era. Depois daquele dia nunca mais tive coragem de falar nada! (BARROS NETO, 2004, p. 71)

Há ainda os seguintes depoimentos que tipificam as práticas de gestão nos Correios sob os militares:

Um dia o coronel (Diretor Regional de São Paulo na década de 70) chegou no meu CDD (Centro de Distribuição Domiciliária) para uma visita. Para meu azar, os carteiros já tinham saído para a rua, mas tinha ficado 
em cima de uma bancada um montinho de cartas. O coronel me perguntou o que era aquilo e eu disse que eram cartas que provavelmente algum carteiro tinha esquecido. Pra quê! O homem disse 'negão, segura na broxa porque vou puxar a escada' e no dia seguinte recebi o comunicado que estava dispensado da chefia e transferido para Sorocaba. Rodei o interior todo, sem chefiar mais nada, [...]. Com os coronéis era assim, a gente tinha que saber de tudo e fazer tudo certinho, se não, dançava feio. (BARROS NETO, 2004, p. 71)

As práticas autoritárias também ampliaram o número de punições ao impedir as ações reivindicatórias dos trabalhadores:

Teve uma vez, acho que era final de 79, que prometeram para nós um aumento que não veio, aí o pessoal resolveu fazer um abaixo-assinado questionando a empresa sobre o tal aumento e mandamos para a GAP [na época era a Gerência de Administração de Pessoal]. Três dias depois todo mundo do setor foi mandado embora. (BARROS NETO, 2004, p. 71)

Diante desses depoimentos, verifica-se que a reorganização do trabalho foi realizada em um momento em que as relações de trabalho na ECT estavam baseadas no autoritarismo militar. A lógica militarista que valoriza e enfatiza a disciplina, a ordem e a hierarquia tornaram-se parte das práticas cotidianas, presente em todo o processo operacional e organizacional da empresa. Com isso, contestações às ordens e às rotinas de trabalho eram não apenas ignoradas, mas combatidas e perseguidas pelos gestores. Elementos que ensejam práticas rotineiras e autoritárias de gestão pelo mecanismo do poder militar, sem necessidade de consenso ou hegemonia; uma legitimidade garantida, portanto, pela força.

É importante ressaltar que essas práticas foram implantas nos Correios com uma clara noção de hierarquia e rígida disciplina, segundo Barros Neto (2004). De acordo com esse autor, durante muito tempo as punições eram utilizadas para intimidar e pressionar coletivamente os funcionários. Isso fica claro ao se notar que ao punir um funcionário a penalidade que lhe era aplicada era divulgada nos meios de comunicação interna da empresa, além de ser lida em voz alta para todos os empregados do setor de trabalho do funcionário punido e afixada nos quadros de aviso das unidades de trabalho. Segundo esse autor, era prática comum 
na empresa durante o regime militar o discurso relacionado ao dever do funcionário de sempre obedecer e somente depois questionar.

Com isso, visualiza-se que a constituição de uma disciplina fabril baseada no ethos militar estava presente na ECT assim como estivera nas fábricas do século XIX, como nos mostra Perrot (1989).

Nesse contexto, o salário pago pela ECT aos trabalhadores de nível básico (carteiros, mensageiros e executantes operacionais) e estabelecido no PCCS de 1974, segundo Bovo (1997), correspondia a 2,46 salários mínimos à época, caso fossem considerados os estados da Federação que pagavam o maior salário, ou seja, 3,48 salários mínimos, caso fossem considerados os menores. De acordo com os levantamentos de Barros Neto (2004), não houve a recomposição do salário dos trabalhadores no final da década de 1970 e, principalmente, nos anos de 1980, o que diminuiu o poder de compra dos funcionários da ECT. Ao mesmo tempo, a rotatividade dos trabalhadores da ECT aumentou significativamente, sobretudo entre 1984 e 1987.

$\mathrm{O}$ aumento da rotatividade relaciona-se, também, a outro fenômeno: o crescente aumento das mobilizações sindicais ocorridas no período. ${ }^{8}$ Os trabalhadores da ECT, assim como os demais servidores públicos, estavam proibidos de se sindicalizarem e, juridicamente, manifestarem-se por meio de greves pela Constituição de 1967 - promulgada, portanto, pela ditadura militar.

Não obstante, os funcionários da ECT organizavam-se em associações. Os movimentos reivindicatórios na ECT remontam a 1979, quando foi registrado um protesto pela recomposição salarial, melhoria no atendimento médico e direito à criação de um sindicato. No entanto, só conseguiram a demissão dos trabalhadores que assumiram explicitamente a direção do movimento. (BOVO, 1997)

Em 1985, no entanto, foi registrada a primeira greve dos ecetistas em São Paulo, sendo seguida por outros estados da Federação, por reajuste salarial. Nesse ano, ocorreram duas greves: em março e maio. Dentre outras consequências do movimento destacam-se cerca de três mil demissões e o

8 A década de 1980 assistiu ao protagonismo de "novos atores sociais", dentre os quais se incluem os sindicatos. Cf. SADER, 1988. 
fechamento de algumas associações dos trabalhadores. Em 1986 foi registrado outro movimento grevista, reivindicando jornada de trabalho de 48 horas semanais com sábado livre, readmissão dos demitidos ${ }^{9}$ e manutenção do monopólio estatal. ${ }^{10}$ No ano seguinte houve novamente uma greve, mas a maior da categoria ecetista foi registra em 1988, de 12 de julho a 11 de agosto, por reposição salarial, alcançando parcialmente o pleito. (BOVO, 1997)

A proibição constitucional do direito de greve e o autoritarismo dos gestores da ECT à época levaram à demissão maciça de trabalhadores grevistas e até mesmo à recusa em receber a pauta de reivindicações em 1986, segundo Bovo (1997).

Em 1988, com a promulgação da nova Constituição Federal, no entanto, o direito de greve foi estendido aos trabalhadores das empresas públicas e, por conseguinte, aos funcionários da ECT. Com isso, naquele mesmo ano foram criados os sindicatos estaduais da categoria a partir das associações e a entidade com representação nacional: Federação Nacional dos Trabalhadores em Empresas de Correios e Telégrafos e Similares (FENTECT).

Ao final da década de 1980, a qualidade dos serviços nos Correios deteriorou-se bastante em decorrência das demissões e da impossibilidade de realizar novas contratações e treinamentos dos funcionários conforme as necessidades.

Apesar disso, a ECT informa que em 1984 o Instituto Gallup apontou a empresa como a de maior credibilidade no país, fato que teria sido reiterado em pesquisa de 1987, que atestou o alto índice de pontualidade e qualidade dos serviços prestados, além de obter o prêmio de melhor empresa em termos de produtividade pela Revista Exame em sua edição "Melhores e Maiores".

Nessa época, já ecoava fortemente no Brasil o discurso da reestruturação produtiva e da liberalização, o que direcionou as estratégias gerenciais acionadas a partir de então pelos gestores públicos e pela ECT. Ao mesmo

9 As demissões criaram, nas décadas seguintes, reivindicações para anistiar os trabalhadores perseguidos e demitidos durante as greves.

10 À época, empresas de courier tentavam entrar no mercado postal brasileiro, como discutido na seção 2.2. A defesa do monopólio será uma bandeira presente em todos os movimentos reivindicatórios nas décadas seguintes. 
tempo, o setor postal internacional já havia iniciado os processos de reestruturação dos marcos regulatórios. É nesse contexto que a ECT adentra os anos de 1990, quando projetos para reestruturação da estatal e do sistema postal brasileiro estariam nas estratégias do governo federal.

\section{CONSIDERAÇÕES FINAIS}

A criação da ECT em 1969 foi uma ação, à época, única no contexto internacional. Somente na década de 1980 foram desencadeados processos para transformar departamentos de correios em empresas públicas.

A diferença substancial entre os dois momentos está na intensidade do processo e na velocidade das mudanças. Os países que iniciaram a reforma de seus serviços postais na década de 1980 fizeram as reestruturações nos modelos organizacionais dos correios já considerando a liberalização de mercado e a privatização do sistema.

Ao voltarmo-nos para o cenário nacional para compreender o setor postal brasileiro, deparamo-nos com uma situação bastante diversa, que na década de 1970 já se configurava, efetivamente, como uma empresa pública herdeira do antigo Departamento de Correios e Telégrafos.

De forma esquemática, o quadro 3, a seguir, sintetiza as principais diferenças entre o Departamento de Correios e a ECT:

QUADRO 3 - PRINCIPAIS ALTERAÇÕES COM A CORPORATIZAÇÃO DA ECT EM 1969

\begin{tabular}{|l|l|}
\hline Departamento de Correios e Telégrafos & Empresa Brasileira de Correios e Telégrafos \\
\hline Vinculado à Administração Pública Direta & Órgão da Administração Pública Indireta \\
\hline Órgão estatal & Empresa pública (integralmente do Estado) \\
\hline Funcionários públicos estatutários & $\begin{array}{l}\text { Empregados públicos celetistas (sem } \\
\text { concurso para ingresso até 1988) }\end{array}$ \\
\hline Transporte de cartas e encomendas & $\begin{array}{l}\text { Diversificação dos serviços: cartas, encomendas, } \\
\text { serviços expressos (SEDEX), etc. }\end{array}$ \\
\hline $\begin{array}{l}\text { Ausência de autonomia } \\
\text { administrativa e gerencial }\end{array}$ & $\begin{array}{l}\text { Garantida a autonomia gerencial e } \\
\text { administrativa; Introdução da administração } \\
\text { científica dos processos de trabalho. }\end{array}$ \\
\hline Monopólio de cartas & $\begin{array}{l}\text { Regulamentação de serviços monopolizados } \\
\text { em 1978: cartas, encomendas, telégrafos. }\end{array}$ \\
\hline
\end{tabular}

Fonte: Elaborado pelo autor.

Para os trabalhadores, a criação da ECT também significou profundas mudanças. Dentre elas, os funcionários passaram a ser regidos pela 
Consolidação das Leis do Trabalho. Com isso, os concursos públicos foram suspensos e retomados somente com a Constituição de 1988, o que propiciou a livre contratação e demissão.

Concomitantemente, a ECT expandiu a oferta de serviços com a criação de serviços de remessas expressas e ampliou as parcerias com órgãos da administração pública para prestação de serviços nas agências. Ao mesmo tempo, combateu a violação ao monopólio postal, inclusive acionando os instrumentos legais e policiais quando cabíveis e denunciando as manobras, nos anos 1980, de multinacionais interessadas em atuar em segmentos do mercado postal nacional.

Na década de 1970 houve a estruturação da organização do processo de trabalho e a incorporação de princípios da administração científica por meio do Projeto Eco, visando aumentar a produtividade e a eficiência do trabalho. O objetivo foi alcançado e a estatal foi agraciada com prêmios que passou a receber pela qualidade dos serviços prestados já na década de 1980.

As relações de trabalho no contexto da ditadura militar, no entanto, foram marcadas pelo autoritarismo dos gestores militares. As punições dos movimentos reivindicatórios e dos trabalhadores que questionavam as prescrições das tarefas resultaram em demissões em massa e na alta rotatividade dos trabalhadores, sobretudo operacionais.

Por um lado, isso significa que as ações das associações dos trabalhadores foram fortalecidas e, no contexto dos novos movimentos sociais, deixaram de ser atores coadjuvantes no processo de modernização da ECT. Ao mesmo tempo, contudo, a qualidade dos serviços operacionais começou a declinar. Juntamente com isso, o lucro da estatal passou a ser considerado insuficiente, no final da década de 1980, para aumentar os investimentos necessários.

Na década de 1990, as transformações postais no contexto internacional influenciaram as estratégias governamentais para o setor postal brasileiro, como será discutido no próximo capítulo. 